\section{AB0861-HPR MENTAL DISORDERS AND GASTROINTESTINAL SYMPTOMS IN RHEUMATIC DISEASES: A CROSS- SECTIONAL STUDY}

F. S. laquinta ${ }^{1}$, R. Spagnuolo ${ }^{2}$, S. Naty ${ }^{3}$, P. Doldo ${ }^{2}$, R. D. Grembiale ${ }^{3} .{ }^{1}$ University "Magna Graecia" of Catanzaro, Rheumatology Research Unit, Department of Health Sciences, Catanzaro, Italy; ${ }^{2}$ University "Magna Graecia" of Catanzaro AOU Mater Domini - Gastroenterology Unit, Department of Experimental and Clinical Medicine, Catanzaro, Italy; ${ }^{3}$ University “Magna Graecia" of Catanzaro, Rheumatology Research Unit, Department of Health Sciences, Catanzaro, Italy

Background: Several studies agree that patients with chronic diseases are more likely to have mental health problems. Moreover, Rheumatic Diseases (RD) patients may show gastrointestinal symptoms as result of primary inflammation, secondary involvement or as treatment consequences. A better understanding of the potential association among such symptoms can help to improve treatment and quality of life.

Objectives: The aim of this study was to evaluate the impact of gastrointestinal symptoms (Gl) on mental and social health in RD patients.

Methods: We performed a cross-sectional study of $69 \mathrm{RD}$ patients with primarily osteoarticular symptoms. Patients completed questionnaires on Gl symptoms (belly pain, constipation, diarrhea, disrupted swallowing, gas and bloating, nausea and vomiting, gastroesophageal reflux) and psychosocial changes (anxiety, depression, fatigue, sleep disturbance, pain interference, physical function, satisfaction with participation in social roles), of the Patient-Reported Outcomes Measurement Information System (PROMIS).

Results: Among 69 patients, $34(49.3 \%)$ had a diagnosis of Rheumatoid Arthritis; 35 (50.7\%) had axial spondyloarthritis (i.e. Psoriatic arthritis and Ankylosing Spondylitis). Median disease duration was 7,6 \pm 4 years and over one-third (36.2\%) of patients had active disease. Most patients reported psychosocial changes and GI symptoms, as shown in Table 1. More specifically, figure 1 (A-G) shows that fatigue was associated with belly pain and bloating $(p<0.001)$, and with constipation, diarrhea, disrupted swallowing and gastroesophageal reflux $(p<0.01)$. Anxiety was related to disrupted swallowing and gastroesophageal reflux $(p<0.01)$ whereas depressive symptoms were associated with belly pain $(p<0.001)$, bloating and gastroesophageal reflux $(p<0.01)$. Moreover, all gastrointestinal symptoms affected sleep quality. Finally, such symptoms significantly affected patients' social domain especially regarding satisfaction with participation in social roles $(p<0.05$ for belly pain and diarrhea, $p<0.01$ for bloating and disrupted swallowing) and physical functions $(p<0.001$ for belly pain, diarrhea, disrupted swallowing; $p<0.01$ for constipation, bloating and nausea and vomiting; $p<0.05$ for gastroesophageal reflux).

Table 1.

\begin{tabular}{|c|c|c|}
\hline$N=69$ & Yes & $\begin{array}{l}\text { Median } t \text {-Score } \\
\pm \text { SD }\end{array}$ \\
\hline \multicolumn{3}{|l|}{$\begin{array}{l}\text { Mental and social } \\
\text { Health PROMIS }\end{array}$} \\
\hline Anxiety, $n(\%)$ & $48(69,6)$ & $55,2 \pm 10$ \\
\hline Depression, $n(\%)$ & $40(58)$ & $51,8 \pm 10$ \\
\hline Fatigue, $n(\%)$ & $52(75,4)$ & $57,7 \pm 10$ \\
\hline $\begin{array}{l}\text { Sleep Disturbance, } \\
\quad n(\%)\end{array}$ & $44(63,8)$ & $52 \pm 10$ \\
\hline $\begin{array}{l}\text { Pain interference, } \\
n(\%)\end{array}$ & $62(89,9)$ & $60,9 \pm 8$ \\
\hline $\begin{array}{l}\text { Physical Function, } \\
n(\%)\end{array}$ & $64(92,8)$ & $39,4 \pm 8$ \\
\hline $\begin{array}{l}\text { Satisfaction with par- } \\
\text { ticipation in social } \\
\text { roles, } n(\%)\end{array}$ & $21(30,4)$ & $45,2 \pm 10$ \\
\hline \multicolumn{3}{|l|}{ GI-PROMIS } \\
\hline Belly pain, $n(\%)$ & $35(50,7)$ & $50,6 \pm 14$ \\
\hline Constipation, $n(\%)$ & $36(52,2)$ & $51,2 \pm 10$ \\
\hline Diarrhea, $n(\%)$ & $20(29)$ & $45,2 \pm 8$ \\
\hline $\begin{array}{l}\text { Disrupted Swallowing, } \\
\text { n (\%) }\end{array}$ & $31(44,9)$ & $51 \pm 10$ \\
\hline $\begin{array}{l}\text { Gas and Bloating, } \\
\quad n(\%)\end{array}$ & $54(78,3)$ & $55,5 \pm 8$ \\
\hline $\begin{array}{l}\text { Nausea and Vomiting, } \\
n(\%)\end{array}$ & $32(46,4)$ & $49,9 \pm 8$ \\
\hline $\begin{array}{l}\text { Gastroesophageal } \\
\text { Reflux, } n(\%)\end{array}$ & $27(39,1)$ & $49,1 \pm 11$ \\
\hline
\end{tabular}

Continuous variables are expressed as median and standard deviation. Categorical variables are expressed as number and proportion. GI and psychosocial changes scores were dichotomized for the use of categorical variables.
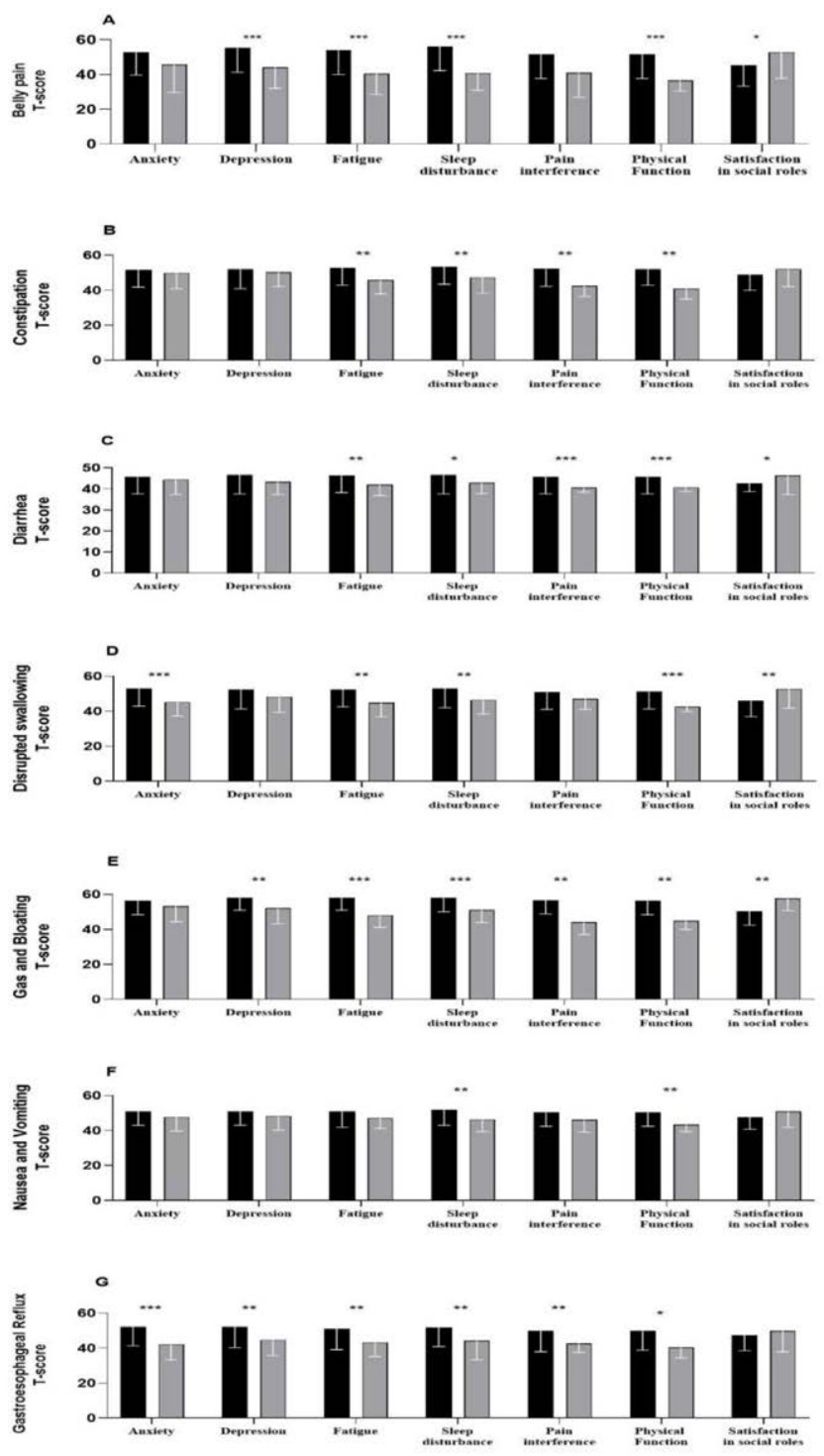

Figure 1. A-G: Gl symptoms in RD patients across dichotomized psychosocial symptoms (Yes in Black/No in grey). The overall $p$-value was calculated by the Mann-Whitney non-parametric test for independent samples.

Conclusion: This study highlights the association between Gl symptoms and psychosocial changes in RD patients. The use of validated Patients-Reported Outcomes, especially in clinical practice, may help to better define the impact of such symptoms on patients' quality of life and then evaluate patients' needs in a global dimension.

REFERENCES:

[1] P. T. Kröner, O. A. Tolaymat, A. W. Bowman, A. Abril, e B. E. Lacy, Gastrointestinal Manifestations of Rheumatological Diseases, Am. J. Gastroenterol., 2019.

[2] Mancina RM et al. Gastrointestinal Symptoms of and Psychosocial Changes in Inflammatory Bowel Disease: A Nursing-Led Cross-Sectional Study of Patients in Clinical Remission. Medicina (Kaunas). 2020 Jan 20;56(1):45.

Disclosure of Interests: None declared

DOI: 10.1136/annrheumdis-2021-eular.1919

\section{AB0862-HPR THE RELATIONSHIP BETWEEN ANAEROBIC EXERCISE CAPACITY AND LOWER EXTREMITY FUNCTIONALITY IN PATIENTS WITH FAMILIAL MEDITERRANEAN FEVER}

M. E. Acar ${ }^{1}$, D. Bayraktar ${ }^{2}$, S. Gucenmez ${ }^{3}$, D. C. Saraç², N. Buker ${ }^{2}$, U. Z. Kocak ${ }^{2}$, D. Solmaz ${ }^{4}$, S. Akar ${ }^{4} .^{1}$ Izmir Katip Celebi University, Institute of Health Sciences, Department of Physiotherapy and Rehabilitation, Izmir, Turkey; ${ }^{2}$ Izmir Katip Celebi University, Faculty of Health Sciences, Department of Physiotherapy and Rehabilitation, Izmir, Turkey; ${ }^{3}$ Izmir Katip Celebi University, 
Ataturk Education and Research Hospital, Rheumatology Clinic, Izmir, Turkey; ${ }^{4}$ Izmir Katip Celebi Unviersity, Faculty of Medicine, Department of Internal Medicine, Division of Rheumatology, Izmir, Turkey

Background: Familial Mediterranean fever (FMF) is an auto-inflammatory disease commonly affects people from Mediterranean basin. It is characterized by acute self-limiting inflammatory attacks of serous membranes. The disease is commonly associated with musculoskeletal symptoms of lower extremities such as arthritis, exercise induced leg pain, as well as protracted febrile myalgia. The term of anaerobic exercise capacity describes the ability of performing quick and explosive tasks such as stair climbing and brisk walking. It is well known that anaerobic exercise capacity is closely related to functional status.

Objectives: To assess the relationship between anaerobic exercise capacity and lower extremity functionality in patients with FMF.

Methods: Twenty-eight FMF patients (57\% female) were included in the study. Median age was 33.5 (IQR 25/75: 23.3/44.3) years, median body mass index was 24.3 (IQR 25/75: $21.0 / 27.8) \mathrm{kg} / \mathrm{m}^{2}$ median time since symptom onset was 20.0 (IQR 25/75: 11.5/24.5) years, median time since diagnosis was 10.0 (IQR 25/75: 3.75/17.5) years, and median colchicine dosage was 1.5 (IQR 25/75: 1.0/1.5) $\mathrm{mg} /$ day. Anaerobic exercise capacity was measured with Wingate Anaerobic Test by using a cycle ergometer. Peak power (watt $/ \mathrm{kg}$ ) and average power (watt $/ \mathrm{kg}$ ) were calculated. Stair climbing, standing from a chair, and walking were assessed by using 9-step stair climb test, 10-repetition chair stand test, and 6 -minute walking distance, respectively. Spearman's rank-order correlation test was used to analyse the relationships between anaerobic exercise capacity and lower extremity functional tests.

Results: The results of the anaerobic exercise capacity and lower extremity functional test scores of patients with FMF were summarized in table 1. Moderate relationships were found between both peak and average anaerobic exercise capacities and lower extremity functional status tests (Table 1, p<0.05). Six-minute walking distance has the strongest association with both peak (rho: .672, $\mathrm{p}<0.001$ ) and average (rho: .689, $\mathrm{p}<0.001$ ) anaerobic exercise capacity.

Table 1. Anaerobic exercise capacity scores and lower extremity functionality as well as the relationships between anaerobic capacity and functional tests in patient with familial Mediterranean fever.

\begin{tabular}{|c|c|c|c|}
\hline \multirow[t]{2}{*}{ Characteristics } & \multirow[t]{2}{*}{$\begin{array}{l}\text { Median (IQR 25/75) } \\
(\mathrm{n}: 28)\end{array}$} & \multicolumn{2}{|c|}{$\begin{array}{l}\text { The correlation results, rho, } \\
\text { p values }\end{array}$} \\
\hline & & $\begin{array}{l}\text { Peak Power } \\
\text { (watt/kg) }\end{array}$ & $\begin{array}{l}\text { Average Power } \\
\text { (watt/kg) }\end{array}$ \\
\hline 9-step stair climb test (seconds) & $5.7(5.1 / 6.4)$ & $\begin{array}{l}-.590^{\star} \\
\mathrm{p}: 0.001\end{array}$ & $\begin{array}{l}-.648^{\star} \\
\text { p: } 0.001\end{array}$ \\
\hline 10-repetition chair stand test (seconds) & $16.6(13.7 / 18.7)$ & $\begin{array}{l}-.493^{\star} \\
\mathrm{p}: 0.008\end{array}$ & $\begin{array}{l}-.476^{\star} \\
\mathrm{p}: 0.010\end{array}$ \\
\hline 6-minute walking distance (meters) & $594.1(551.1 / 643.3)$ & $\begin{array}{l}.672^{\star} \\
\mathrm{p}<0.001\end{array}$ & $\begin{array}{l}.689^{\star} \\
\mathrm{p}<0.001\end{array}$ \\
\hline $\begin{array}{l}\text { Peak power (watt/kg) } \\
\text { Average power (watt/kg) }\end{array}$ & $\begin{array}{l}5.8(4.1 / 7.9) \\
4.6(3.1 / 5.9)\end{array}$ & & \\
\hline
\end{tabular}

IQR 25/75: Interquartile range between $25^{\text {th }}$ and $75^{\text {th }}$ percentiles; kg: kilograms, *Spearman's rank-order correlation test, $p<0.05$.

Conclusion: According to our results, anaerobic exercise capacity is related to lower extremity functional status in patients with FMF. Improving anaerobic capacity by using optimal rehabilitation programs including speed and agility exercises may help to improve anaerobic exercise capacity, and consequently lower extremity functionality in those patients.

Disclosure of Interests: None declared

DOI: 10.1136/annrheumdis-2021-eular.2380

\section{AB0863-HPR FUNCTIONAL STATUS ASSESSMENT THROUGH SELF-REPORTED QUESTIONNAIRES IN RHEUMATIC DISEASES}

P. Herrera-Sandate ${ }^{1}$, D. Vega-Morales ${ }^{1}$, A. L. De-Leon-lbarra ${ }^{1}$, P. ValdesTorres $^{2}$, L. A. Chavez-Alvarez ${ }^{1}$, A. Limon-del Toro ${ }^{1}$, I. D. J. Hernandez-Galarza ${ }^{1}$, R. Pineda-Sic ${ }^{1}$, D. Á. Galarza-Delgado ${ }^{1}{ }^{1}$ Hospital Universitario Dr. José Eleuterio González, Rheumatology Service, Monterrey, Mexico; ${ }^{2}$ Hospital Universitario Dr. José Eleuterio González, Sports Medicine and Physical Rehabilitation Department, Monterrey, Mexico

Background: Health and disease status assessment is of paramount importance in rheumatic diseases. Self-report functional status questionnaires provide a cost and time-efficient means of systematic evaluation for physicians. The Health Assessment Questionnaire (HAQ) is one of the most utilized comprehensive measures of outcome, and is divided in 8 sections of activity domains, namely, dressing, arising, eating, walking, hygiene, reach, grip and outside activities. Other disease-specific instruments such as the Western Ontario and McMaster Osteoarthritis Index (WOMAC) share most of the functional domains evaluated by $\mathrm{HAQ}$, whereas Bath Ankylosing Spondylitis Disease Activity Index (BASDAI) and WOMAC share domains mostly regarding pain and stiffness. Here, we present the results of the application of self-administered surveys in a thirdlevel reference center in Mexico.

Objectives: Determine the functional status and most affected activity domains of patients with rheumatic diseases measured by generic (HAQ) and disease-specific (WOMAC and BASDAI) questionnaires in a reference center of northeastern Mexico.

Methods: We carried out a cross-sectional study in Rheumatology consultation in University Hospital "Dr. José Eleuterio González" in Monterrey, Mexico from August 2019 to December 2020. Nursery personnel systematically applied self-reported questionnaires $\mathrm{HAQ}$, WOMAC and BASDAl in patients during their medical follow-up. Patient-reported outcomes were categorized by HAQ activity domains and/or pain and stiffness symptoms in WOMAC and BASDAI. Demographical characteristics were retrieved as well.

Results: Demographic characteristics are shown in Table 1. HAQ showed a higher prevalence of difficulty performing daily activities in the Grip domain. WOMAC question regarding heavy domestic duties had the higher degree of difficulty, as well as pain ascending stairs and stiffness after awakening. Fatigue was the most severe symptom in BASDAl, followed by pain in areas tender to touch and pressure and stiffness after awakening

Conclusion: Disease activity and functional status impact is present on a mild-moderate level in self-reported questionnaires in the Rheumatology consultation of a northeastern center of reference in Mexico. The most affected domain in patients with rheumatic diseases is Grip domain, the most affected daily activities to perform are heavy domestic duties and the most prevalent symptoms are pain ascending stairs and stiffness after awakening as measured by $\mathrm{HAQ}$, WOMAC and BASDAI, respectively.

\section{REFERENCES:}

[1] Ferreira, P. L., Gonçalves, S. P., Ferreira, L. N., Pereira, L. N., Antunes, P., Gouveia, N., Rodrigues, A., Canhão, H., \& Branco, J. (2016). Assessing quality of life of self-reported rheumatic patients. Rheumatology international, 36(9), 1265-1274. https://doi.org/10.1007/s00296-016-3517-0.

Table 1. Clinical and demographic characteristics of self-reported questionnaires HAQ, WOMAC and BASDAI.

\begin{tabular}{ll}
\hline HAQ & $\mathrm{n}=293$ \\
\hline Female, $\mathrm{n}(\%)$ & $53.96(95.6 \%)$ \\
Age in years, mean (SD) & $51.96(14.2)$ \\
Mean score & 0.8 \\
WOMAC & $\mathrm{n}=59$ \\
Female, $\mathrm{n}(\%)$ & $56(94.9 \%)$ \\
Age in years, mean (SD) & $61.64(9.19)$ \\
Mean score & $35.6 \%$ \\
BASDAl & $\mathrm{n}=8$ \\
Male, $\mathrm{n}(\%)$ & $5(62.5 \%)$ \\
Age in years, mean (SD) & $42.12(14.77)$ \\
Mean score & 4.98
\end{tabular}

HAQ, Health Assessment Questionnaire; WOMAC, Western Ontario and McMaster Osteoarthritis Index; BASDAI, Bath Ankylosing Spondylitis Disease Activity Index; SD, standard deviation.

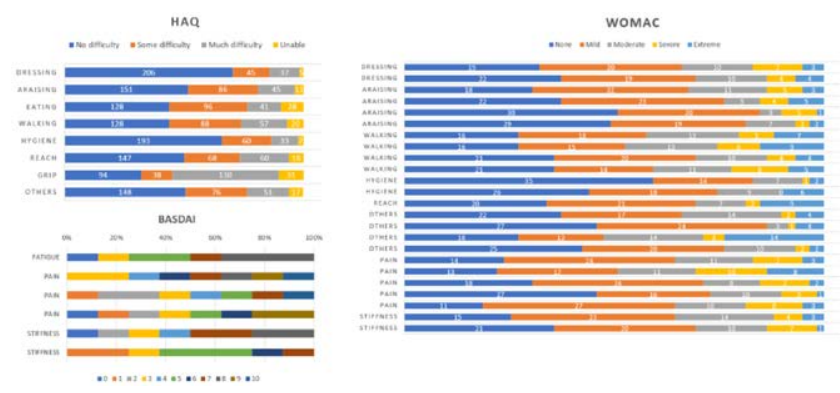

Figure 1. $H A Q$, WOMAC and BASDAI questions arranged by $H A Q$ activity domains and/or symptoms showing the prevalence of difficulty degree per activity.

Disclosure of Interests: None declared DOI: 10.1136/annrheumdis-2021-eular.2781

\section{AB0864-HPR INFLUENCE OF THE TYPE OF PAIN SYNDROME ON THE SEVERITY OF ANXIETY-DEPRESSIVE DISORDERS IN PATIENTS WITH RHEUMATOID ARTHRITIS}

E. Egorova ${ }^{1}$, N. Nikitina2, A. Rebrov ${ }^{1} .{ }^{1}$ Saratov State Medical University name of V.I. Razumovsky Ministry of Health of Russia, Hospital Therapy, 